\title{
Synthesis, characterisation and pre-evaluation of a novel terpolymer as pour point depressants to improve the Malaysian crude oil flowability
}

\author{
Ibrahim Elganidi $^{1} \cdot$ Basem Elarbe $^{1} \cdot$ Norida Ridzuan $^{1} \cdot$ Norhayati Abdullah $^{1}$
}

Received: 16 August 2021 / Accepted: 23 December 2021 / Published online: 7 January 2022

(c) The Author(s) 2022

\begin{abstract}
Wax deposition is considered one of the most serious operational issues in the crude oil pipelines. This issue occurs when the crude oil temperature decreases below the temperature of wax appearance and paraffin wax starts to precipitate on the pipelines' inner walls. As a result, the crude oil flow is impeded because of the precipitated wax. The use of polymeric pour point depressants has obtained significant interest among researchers as an approach of wax control for enhancing the flowability of the waxy crude oil. PPD of poly(behenyl acrylate - co-stearyl methacrylate-co- maleic anhydride) (BA-coSMA-co-MA) was facilely synthesised by the use of free radical polymerisation. The variation of the PPD structure was studied by choosing several essential parameters like monomers ratio, reaction time, initiator concentration, and reaction temperature. Furthermore, viscosity measurement, pour point, and cold finger apparatus have been employed to evaluate the efficiency of the synthesised Polymer. The chemical structure of poly(BA-co-SMA-co-MA) has been identified through the use of Fourier transform infrared as well as nuclear magnetic resonance. The experimental findings demonstrated that the ideal conditions for obtaining the highest yield were $1.5 \%$ initiator concentration, reaction time and temperature of $8 \mathrm{~h}$ and $100{ }^{\circ} \mathrm{C}$, respectively, and monomer ratio of 1:1:1 (BA:SMA:MA). Under these ideal conditions, the prepared terpolymer reduced the crude oil viscosity at $30{ }^{\circ} \mathrm{C}$ and $1500 \mathrm{ppm}$ from 7.2 to $3.2 \mathrm{mPa}$.s. The cold finger experiment demonstrated that after poly(BA-co-SMA-co-MA) was used as a wax inhibitor, the maximum efficiency of paraffin inhibition of $45.6 \%$ was achieved at $200 \mathrm{rpm}$ and $5{ }^{\circ} \mathrm{C}$. Besides, the best performance in depressing the pour point by $\Delta \mathrm{PP} 14{ }^{\circ} \mathrm{C}$ observed at the concentration of $1500 \mathrm{ppm}$, which can change the growth characteristics of wax crystals and delay the aggregation of asphaltene and resin, thus effectively improving the flowability of crude oil.
\end{abstract}

Keywords Wax deposition $\cdot$ Crude oil $\cdot$ Viscosity reduction $\cdot$ Free radical polymerisation $\cdot$ Pour point depressants

\section{Introduction}

It is widely acknowledged that the main components of the crude oil mixture consist of resins, asphaltenes, paraffin, and aromatic hydrocarbons. Paraffins, mainly those with high molecular weight (i.e., wax), are challenging for engineers working mostly within the upstream section of the petroleum industry. The temperature of the crude oil significantly influences the solubility of wax in oil. These waxes tend to

Norhayati Abdullah

yatiabdullah@ump.edu.my

1 Faculty of Chemical and Process Engineering Technology, Universiti Malaysia Pahang, 26300 Pahang, Gambang, Malaysia solidify and precipitate from the oil during the production and transporting of crude oil from upstream to downstream segments, phase changes occur in crude oil, and paraffin wax starts to precipitate out of unrefined oil after the temperature decreases beneath the wax appearance temperature (WAT) (Mohyaldinn et al. 2019). Structural changes in the waxy crude oil include precipitation, deposition, and wax gelation, which make wax networks form cage-like structures that trap crude oil, causing viscosity and pour point to increase, and sometimes pipeline blockage (Elganidi et al. 2021). Besides, wax aggregation in oil pipelines prompts to decrease in the flow rate resulting in an increase in the transportation pressure, thus placing additional load on electricity and pumping costs (Wang et al. 2019). As a result, this will eventually lead to implementing an expensive remediation method and costly downtime in oil production (Madani et al. 2021).

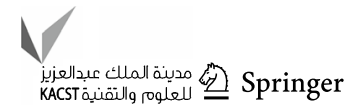


In order to remedy the problems associated with wax precipitation/deposition, multiple techniques have been formulated to handle the wax deposition problem (White et al. 2018). Thermal techniques, like pumping warm water or oil via pipelines and sealing crude pipelines to maintain temperature, as well as mechanical methods, like pigging, which scrapes the pipeline's inner walls to remove deposited wax, are some of the techniques to ensure flow assurance in crude oil pipelines (Alnaimat 2020). However, considering cost, time and energy constraints, chemical techniques have certain advantages over other approaches. For example, by using chemical methods, a chemical group can disrupt the development of wax molecules via co-crystallisation, splitting molecular clusters, or modifying crystal properties. In addition, the synthetic chemicals alter the wax crystals solubility and form layers around wax molecules to separate them from the crude oil and slow the growth of crystals (Deka et al. 2018a). Therefore, among the other techniques, chemical treatment practices have yielded the best performance in mitigating wax precipitation (Jennings and Breitigam 2010; Aiyejina et al. 2011; Elbanna et al. 2017). Moreover, polymeric additive usage has proven to be the most effective and economical method for preventing wax precipitation (Elganidi et al. 2019). Furthermore, many researchers have studied pour point depressant (PPD) efficiency on different types of waxy oil. They revealed that PPDs could reduce crude oil viscosity and improve flowability during transportation (Wang et al. 2011; Chala et al. 2018; Zhu et al. 2018).

In this respect, various chemical additives have been used aiming to resolve the wax deposition problem. Among these, polymers containing long linear alkyl chains and a polar component such as acetate, acrylate, and methacrylate groups have an increased ability to interfere with crude oil crystal wax below their cloud point (Yao et al. 2016). These additives can co-precipitate with the wax, causing steric hindrance during the crystallisation process, thus interfering in the growth and aggregation of wax crystals. This reduces the pour point of the oil and avoids the formation of deposits inside pipes. Some commercial additives, such as poly(ethylene-co-vinyl acetate) (EVA), have presented promising results in reducing the pour point of various types of petroleum (Yang et al. 2017; $\mathrm{Li}$ et al. 2018). In addition, stearyl methacrylate is one of the chain-length alkyl groups, which is a kind of acrylic monomer with a close association with the non-polar solvents and is primarily distributed in PPDs synthesis. Despite the amorphous backbone that prevents oil absorption, poly(stearyl methacrylate) has a tendency to exist in a crystalline form due to the crystalline property of that long-chain of the alkyl groups (Farag 2008). Over the last several years, many studies have been performed on acrylic monomers, considering that the monomers are of the massive multilateral type used to construct acrylate polymers, which is shaped by acid-structure polymers based on acrylic containing carboxylic acid as well as vinyl groups (Ballard and Asua 2018; Yang et al. 2015a).

Furthermore, ideally, acrylic and methacrylic ester groups are one of the chemicals employed for this purpose owing to their high-performance ability to hinder wax deposition as well as flow modifiers (Yang et al. 2015a). A significant number of researchers (Zhu et al. 2004; Darvishi et al. 2013a; Goswami et al. 2019; Ghosh et al. 2017; Yang et al. 2018; Yang et al. 2015b) employed methacrylate and acrylate monomers in manufacturing PPDs polymers because these polymers have reactive vinyl bonds. As a PPD chemical inhibitor, such polymers could improve the crude oil flowability and reduce the wax deposition in the crude oil pipeline. Because of their highly polar functional groups, methacrylate and maleic anhydride polymers have risen in popularity as potential output additives over recent years (Wu et al. 2012; Zhou et al. 2015). (Than et al. 2017) showed the reaction parameters such as behenyl acrylate, stearyl methacrylate, vinyl acetate as well as AIBN as initiator could affect PPD production, and this PPD can decrease the pour point temperature by as much as $15{ }^{\circ} \mathrm{C}$ as well as impact the amount of wax that is deposited by $70 \%$. Behenyl acrylate plays a crucial role in improving the performance of the additive due to the presence of long hydrocarbon chains and polar ends molecules. A maleic anhydride PPD with alkyl linoleate was prepared by (Soliman et al. 2018a), which reduced the pour point temperature by about $18{ }^{\circ} \mathrm{C}$.

Current research aims to screen and pre-evaluate a novel terpolymer of poly (BA-co-SMA-co-MA) as a PPD that could hinder the wax precipitation in the pipelines that carry crude oil. The motivation behind the selection of the utilised monomers in the current research related to specific properties for each chosen monomer, as reported in the previous studies (Wu et al. 2012; Zhou et al. 2015; Than et al. 2017). Also, to the best of our knowledge, no such work has been published to optimise the reaction parameters and evaluate the performance of the synthesised poly(BA-co-SMA-co-MA) polymers. The techniques to characterise the Polymer prepared have been determined using FTIR and HNMR. The effects of operational polymerisation parameters, like initiator concentration, polymerisation time, reaction temperature, and monomer concentration, on the synthesised polymer's yield were screened using a one-factor-at-a-time (OFAT) method. These factors affecting investigational procedures were identified so that future researches could be designed to attain maximum yield of the polymerisation process. Furthermore, the synthesised Polymer's performance was examined through viscosity measurement, pour point evaluation and cold finger experiment. 


\section{Experimental section}

\section{Materials}

Stearyl methacrylate (SMA) (96\%), behenyl acrylate (BA) $(99 \%)$ as well as maleic anhydride (MA) $(<99 \%)$, all supplied by Aladdin chemicals, were used as monomers. Toluene ( $\geq 99 \%)$ was used as a solvent and benzoyl peroxide (BPO; 99\%) was employed as an initiator, and both chemicals were obtained from Sigma-Aldrich.

\section{The preparation of terpolymer}

Behenyl acrylate-co-stearyl methacrylate-co-maleic anhydride was subjected to the polymerisation process through free radical polymerisation, as shown in Fig. 1, in a $250 \mathrm{~mL}$ three-necked glass flask that was fully supplied with a thermometer, a nitrogen gas inlet as well as a magnetic stirrer. Different mole ratios of monomers were used (1:1:1, 2:1:1, $1: 2: 1$, and 1:1:2). When being constantly stirred at $400 \mathrm{rpm}$, the monomer mixture was dispersed in a $50 \mathrm{~mL}$ toluene at a reaction time of $4-12 \mathrm{~h}$ and at a polymerisation temperature of $60-120{ }^{\circ} \mathrm{C}$. Benzoyl peroxide $(0.5-2.5 \mathrm{wt} \%$ of the total number of monomers) was used as an initiator for the reaction and dissolved in a suitable volume of toluene. Later, the initiator solution was inserted dropwise to the reaction mixture every quarter-hour for the initial one hour of the reaction, as asserted previously (Elganidi 2020).

\section{Separation and purification of the terpolymer}

After the polymerisation process was finalised, the solution was let to cool down to the room temperature. After that, the solution was gradually dropped into $70 \mathrm{~mL}$ of methanol with a dropper and rapidly stirred. The necked glass reactor was washed with toluene in a small amount; then the residual liquid was mixed with methanol. The terpolymer was completely precipitated after $2 \mathrm{~h}$ of stirring. After vacuum filtration, the terpolymer was dried in the vacuum oven for twenty-four hours.

\section{Characterisation of the synthesised PPD}

The prepared terpolymer's chemical structure and functional groups have been identified using Fourier transform infrared spectrometer (FTIR) by (Nicolet iS5 FT-IR spectrometer). In this method, the polymer beads were placed over the diamond crystal window at room temperature. Then the pressure was applied to the sample and the ATR touchpoint was pressed to analyse the material. First, the spectrum was scanned within a wavenumber ranging from 400 to $4000 \mathrm{~cm}^{-1}$. In addition, proton nuclear magnetic resonance spectra (H-NMR) of poly(BA-co-SMA-co-MA)<smiles>C/C=C\C(=O)OC(C)(C)CCC</smiles>

Behenyl Acrylate (BA)<smiles>CC=C(C)C(=O)OC(C)(CC)CCCC</smiles>

Stearyl Methacrylate (SMA)<smiles>O=C1C=CC(=O)O1</smiles>

Maleic Anhydride (MA)<smiles>CCCC(CC(CC)C(=O)OC([14CH3])OC1CC2C[C+](C)(CO2)C1=O)OC(=O)CC(C)(C)C</smiles>

(BA-co-SMA-co-MA)

Fig. 1 Schematic of free radical polymerization of poly(BA-co-SMA-co-MA) 
were obtained to confirm the chemical structure of the prepared Polymer using Bruker ultra-shield plus spectrometer at $500 \mathrm{MHz}$. Next, the Samples were inspected using a $5 \mathrm{~mm}$ $1 \mathrm{H}$ dual-probe head at $27^{\circ} \mathrm{C}$ using deuterated chloroform $\left(\mathrm{CDCl}_{3}\right)$ as a solvent. The spectra were collected into $32 \mathrm{~K}$ data spots and treated utilising exponential multiplication with a $2 \mathrm{~Hz}$ line that is broadening into $128 \mathrm{~K}$ spectra.

\section{Characteristics of the crude oil}

The physical and chemical properties of the used crude oil, like viscosity, API, WAT, and pour point, were determined as reported previously by (Subramanie et al. 2019). WAT was identified with a differential scanning calorimeter, and the pour point was calculated with a Koehler cloud/ pour point bath. API and viscosity were computed with a Micromeritics AccuPyc II 1340 pycnometer and Brookfield DV-III viscometer, respectively.

\section{Evaluation performance of terpolymer}

The prepared terpolymer's efficiency in enhancing the lowtemperature flowability of waxy crude oil was evaluated by measuring the rheological properties, pour point and the wax deposition rate with and without polymeric additive by using the following methods.

\section{Viscosity evaluation}

A Brookfield DV-III viscometer with the Spindle model 31 was used to determine the crude oil's apparent dynamic viscosity with and without the BA-co-SMA-co-MA addition.
The methods that are employed met the ASTM D5002-99 as well as ASTM D445-06 standards. Before measuring viscosity, the crude oil sample was heated until the temperature was above the WAT for the complete dissolution of paraffin crystals. After that, $2 \mathrm{~mL}$ of PPD diluted in toluene and $8 \mathrm{~mL}$ of crude oil were transferred to a stainless-steel cylinder with a casing linked to a circulating thermostat water bath. Then, the PPD's influence on the crude oil's rheological behaviour was studied.

\section{Cold finger device}

A cold finger apparatus was utilised, as depicted in Fig. 2 in the study of wax deposition rate in crude oil after the PPD that had been synthesised was used. The experiments were repeated three times. The cold finger experiment was performed at a water bath temperature of $50{ }^{\circ} \mathrm{C}$ for $2 \mathrm{~h}$. The impeller's stirring speed ranged from 100 to $600 \mathrm{rpm}$, and the finger temperatures were set between 5 and $20^{\circ} \mathrm{C}$. $300 \mathrm{~mL}$ of crude oil was transferred to a vessel and injected with $10 \mathrm{~mL}$ of a wax inhibitor for each run. The wax was finally being scraped from the cold U-tube finger and weighed, and the efficacy of paraffin inhibition (PIE) was computed utilising Eq. 1.

$\operatorname{PIE}(\%)=(W f-W t) /(W f) * 100$

where $\mathrm{W} t$ is the amount of deposited wax after chemical treatment $(\mathrm{g})$, and $\mathrm{W} f$ is the reference quantity of deposited wax without the use of the prepared PPD (g) (Bello et al. 2005).

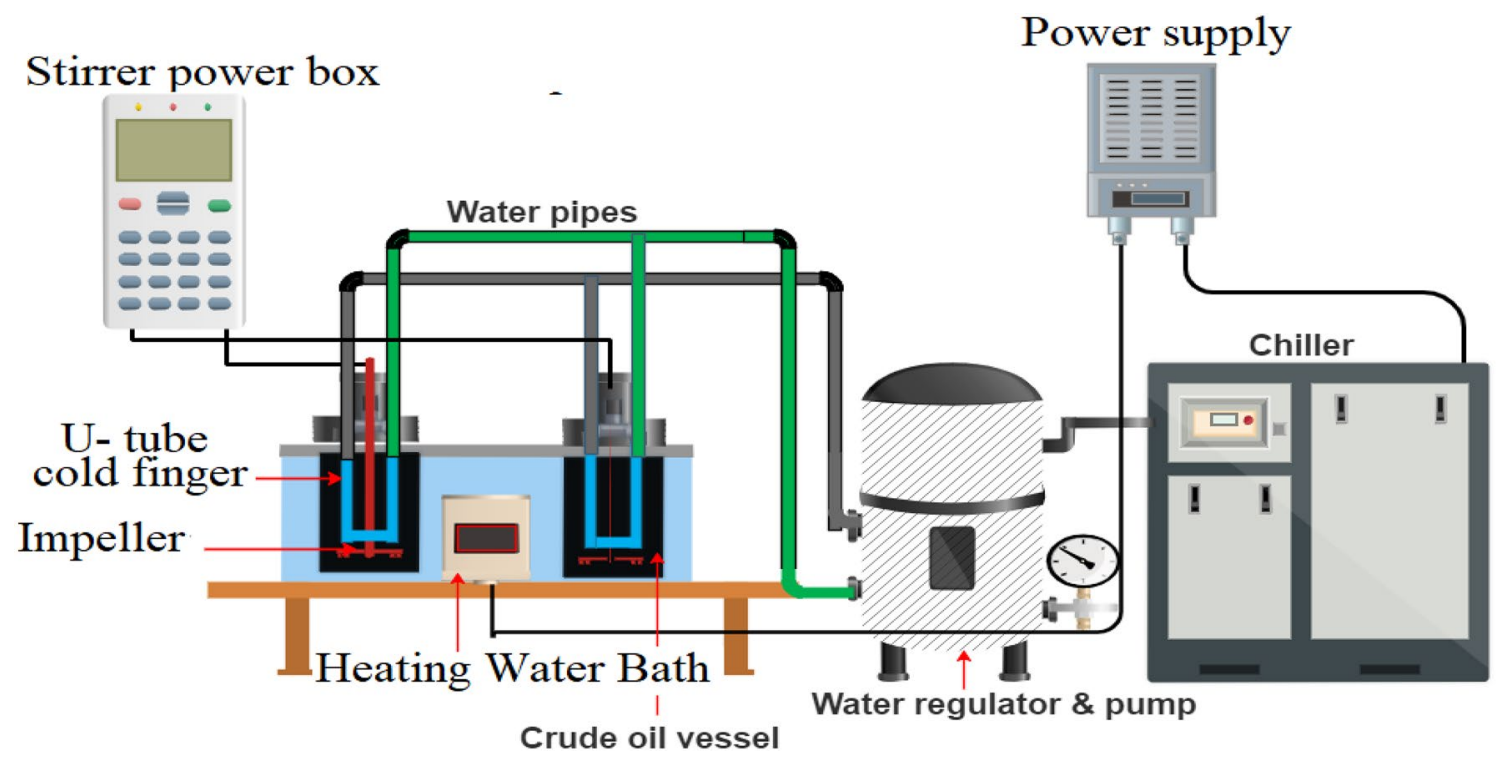

Fig. 2 Cold finger setup 


\section{Pour point (PP) evaluation}

The lowest temperature at which the crude oil fluid becomes semi-solid and cannot move freely due to wax's crystallisation, known as pour point, was determined using a pour point bath supplied by Koehler. Besides, the pour point temperature of both treated and untreated crude oil samples was defined to comply with the ASTM D97 standard (Speight 2015; Ghosh and Das 2014). Consequently, $100 \mathrm{~mL}$ of the crude oil was heated to $50{ }^{\circ} \mathrm{C}$ in an oven and kept overnight to ensure that the wax crystals had dissolved entirely (Anisuzzaman et al. 2017). The synthesised polymer samples were prepared with different concentrations $(500,1000,1500$, and 2000 ppm) and then injected into the crude oil. The prepared samples were then placed in pour point test jars, closed tightly by the cork carrying the thermometer to monitor the temperature drop. It was then placed inside a cooling bath to allow the formation of paraffin wax crystals. The temperature reduction observation will be noted every $3{ }^{\circ} \mathrm{C}$, and the movement of fluid will be checked until the crude oil showed no movement when being held in the horizontal position for precisely $5 \mathrm{~s}$. Then, the temperature at which the fluid stops flowing is recorded from the thermometer to represent the fluid's pour point. The results will be presented as the pure crude oil pour point reduction, calculated by Eq. 2 .

pour point reduction $(\Delta \mathrm{pp})=\mathrm{pp}_{\text {pure }}-\mathrm{pp}_{\text {additives }}$

$\mathrm{PP}_{\text {pure }}$ is the pure crude oil pour point, and $\mathrm{PP}_{\text {additive }}$ is the crude oil pour point containing additives (Machado et al. 2001a).

\section{Results and discussion}

The optimum parameters of the polymerisation reaction for a high-yield polymer were investigated. In addition, the polymerisation of poly(BA-co-SMA-co-MA) was conducted to study optimal reaction conditions with OFAT.

\section{Characteristics of crude oil}

The physiochemical characteristics of the used crude oil sample were identified (Table 1). These properties were determined through various analysis methods and instruments, and used to clarify and identify the causes of wax deposition and formulate strategies for resolving wax deposition for the oil and gas industry, as reported previously by (Subramanie et al. 2020).

\section{Characterisation of the synthesised PPD}

Fourier transform infrared (FTIR) spectroscopy The functional groups of the terpolymer prepared were identified
Table 1 Physicochemical properties of the sample of Malaysian crude oil

\begin{tabular}{lc}
\hline Viscosity mPa.s at $35{ }^{\circ} \mathrm{C}$ & 5.67 \\
Density, $\mathrm{g} / \mathrm{cm}^{3}$ & 0.814 \\
API & 42.4 \\
WAT, ${ }^{\circ} \mathrm{C}$ & 28 \\
Wax content at $20^{\circ}, \%$ & 9.3 \\
Pour point, ${ }^{\circ} \mathrm{C}$ & 11 \\
\hline
\end{tabular}

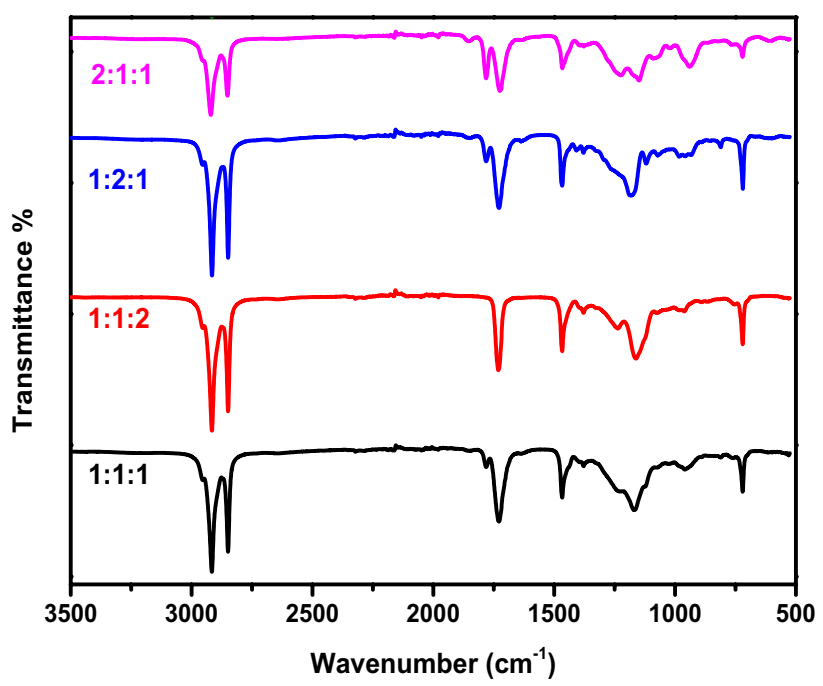

Fig. 3 FTIR spectra of the prepared PPD with different ratios of monomers (BA: SMA: MA)

by FTIR characterisation and the positions of poly(BA-coSMA-co-MA) spectra with different mole ratios of monomers are depicted in Fig. 3. The main peaks identified are 1781 and $1728 \mathrm{~cm}^{-1}$ which are characteristics of $\mathrm{C}=\mathrm{O}$ for maleic anhydride and stearyl methacrylate, respectively, similar to the observation by Song, et al. (Song et al. 2005). Also, weak asymmetrical stretching peaks at 835 and $959 \mathrm{~cm}^{-1}$ typify the epoxy group, similar results indicated by Darvishi, et al. (Darvishi et al. 2013b) previously. Consequently, the result shows that methacrylate moiety, a moiety of maleic anhydride, and alkyl chain moiety are present in the synthesised terpolymer. In addition, the absence of peaks between 1640 and $1680 \mathrm{~cm}^{-1}$ which characterise the $\mathrm{C}=\mathrm{C}$ group, confirms the polymerisation reaction's completion. This outcome is in line with prior studies stated by other scholars (Atta et al. 2013).

Proton nuclear magnetic resonance ( ${ }^{1} \mathrm{H}$ NMR) The process of further characterising the terpolymer (BA-co-SMA-coMA) that had already been prepared was conducted using ${ }^{1}$ HNMR analyses to obtain supplementary details on its chemical composition. The synthesised polymer (1:1:1mol BA-co-SMA-co-MA) is shown in Fig. 4. The chemical

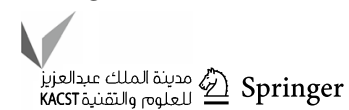


shifts of the prepared terpolymers revealed a strong peak at $0.86 \mathrm{ppm}$, which is attributed to methyl in the methacrylate chain, while the other peaks varying from 1.1 to $1.7 \mathrm{ppm}$ were categorised for methylene of the acrylate chain, which is compatible with the findings of (Upadhyay et al. 2018). Furthermore, the ${ }^{1}$ HNMR proton spectra also revealed chemical shifts at $3.7 \mathrm{ppm}$ as well as $4.1 \mathrm{ppm}$, which was attributed to $\left(-\mathrm{OCH}_{2}\right)$ group in methacrylate and behenyl acrylate, respectively, similar results were observed by (Song et al. 2005). However, as per the prior similar research outcomes by researcher (Zhou et al. 2015), the proton peaks attributed to maleic anhydride monomer are not prominent. Therefore, these findings indicate that the moieties of methacrylate and alkyl chains are present, and this is in line with the FTIR finding.

\section{Screening of the polymerisation parameters}

\section{Effect of monomer ratio}

At $90{ }^{\circ} \mathrm{C}$ reaction temperature, $6 \mathrm{~h}$ of reaction time and 1 wt $\%$ initiator concentration, a series of polymers with different monomer ratios were synthesised. Every PPD's yield was computed as depicted in the experimental results in Fig. 5.

Figure 5 shows that the terpolymer yield's effect is wide when the process of polymerisation is attained at numerous monomer ratios. The molar ratio of monomers BA: MA: SMA) terpolymer affects the yield significantly due to the presence of acrylate groups in the Polymer, which plays a role of a feedstock for chemical additives. For instance, when the behenyl acrylate monomer is excluded from the synthesis process, the yield decreases dramatically to $54 \%$. As seen from Fig. 5, PPD 1 as well as PPD 5 (mole ratio $1: 1: 1$ and $2: 1: 1$ ) significantly increased the prepared polymer yield because of the increase in the high molecular weight monomer concentration of BA in the feed. Long hydrocarbon chains having BA molecules on polar ends are the critical reasons for obtaining better yield from the synthesised polymeric additives, which is also in agreement with the research outcome by (Upadhyay et al. 2018). In terms of monomer ratios, the optimal condition of polymerisation reaction was $1: 1: 1$. It can be concluded from this research that equal molar ratios of stearyl methacrylate, behenyl acrylate, and also maleic anhydride resulted in an optimum yield of the Polymer prepared, and this finding is in agreement with the research outcome of (Zhu et al. 2015).

\section{Influence of reaction temperature}

A series of terpolymer was prepared at differing reaction temperatures that range from 60 to $120^{\circ} \mathrm{C}$, and the polymerisation temperature's effect on the terpolymer yield was investigated, as depicted in Fig. 6. However, the other reaction conditions, such as monomer ratio, reaction time and initiator concentration, were constant (6 h, 1:1:1 and $1 \mathrm{wt} \%$, respectively).

From Fig. 6, it is evident that the synthesised terpolymer's yield continuously increased with reaction temperature that increases from $51 \%$ at $60{ }^{\circ} \mathrm{C}$ until it attains $85.94 \%$ at $100{ }^{\circ} \mathrm{C}$

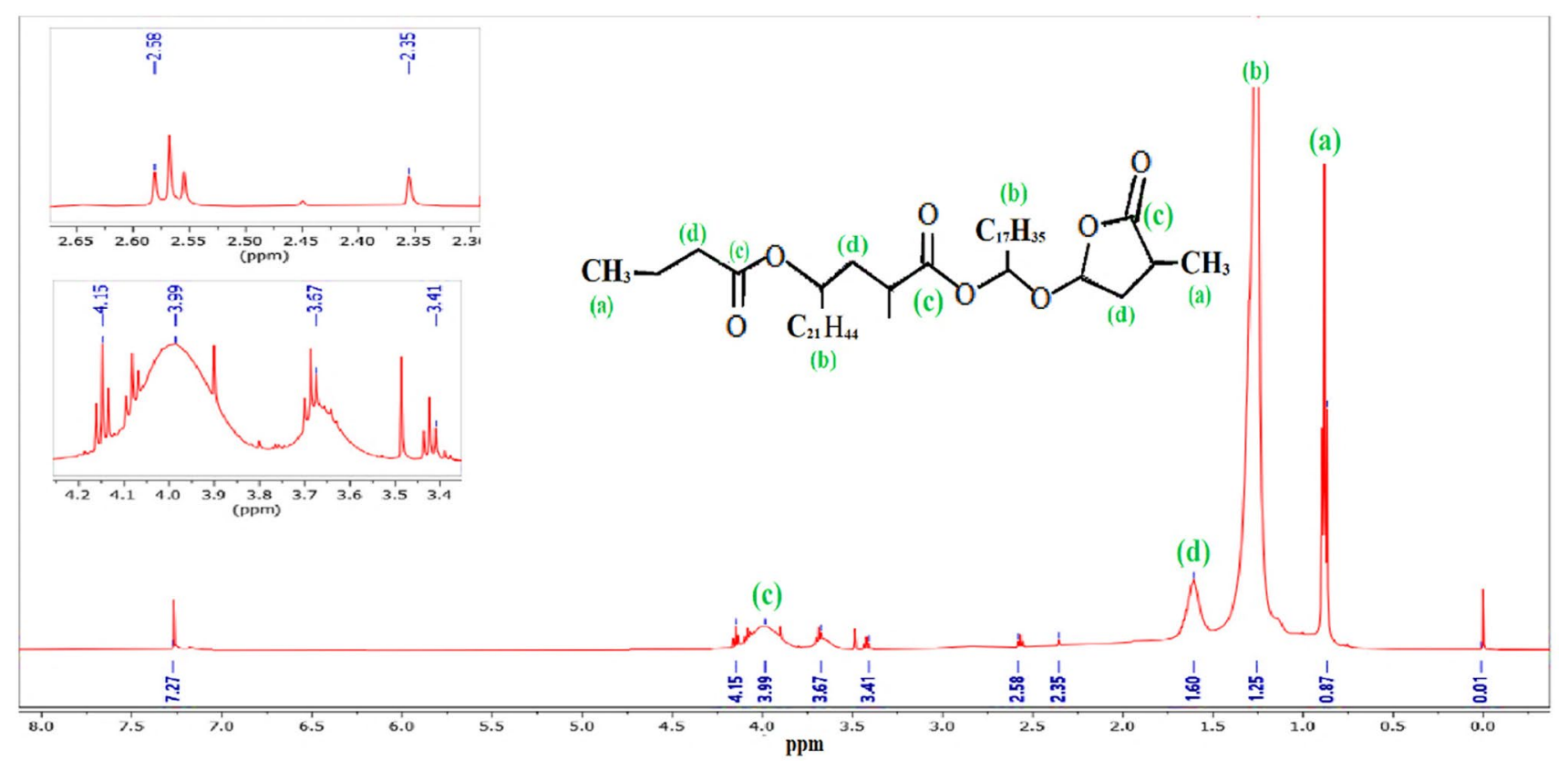

Fig. $4{ }^{1} \mathrm{HNMR}$ spectra of poly(BA-co-SMA-co-MA) 
Fig. 5 Effect of monomer ratio on PPD yield

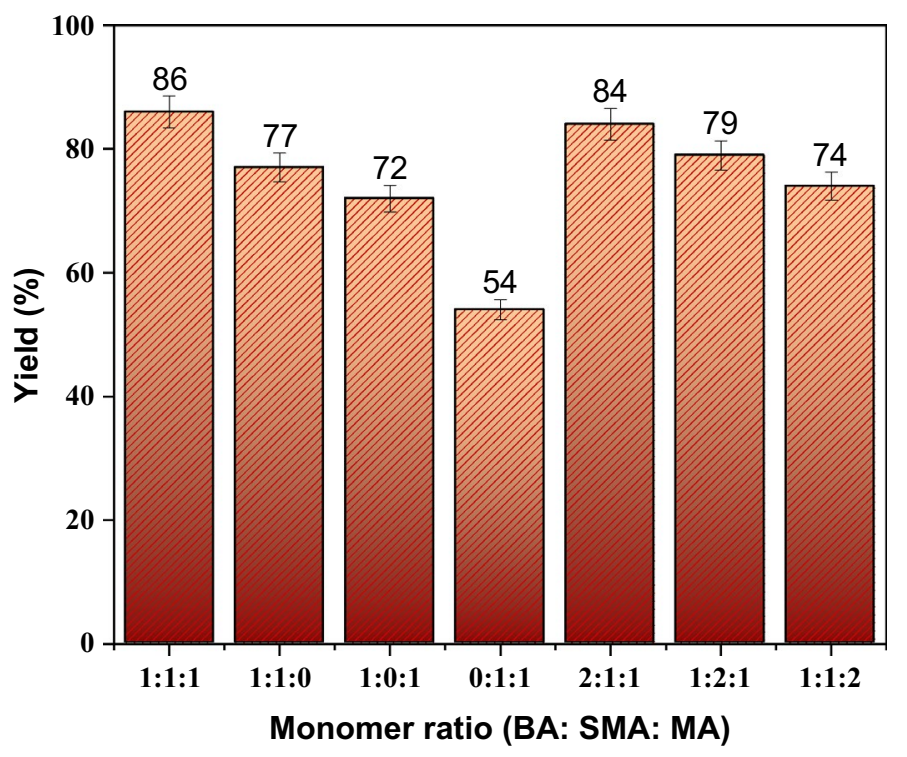

polymerisation yield. Many researchers have also obtained similar results studying the impact of reaction temperature on the polymerisation process as (Lv et al. 2009; Mostafa et al. 2018; Sabaa et al. 2010). Consequently, the condition deemed optimum to complete the polymerisation temperature and attain the highest terpolymer yield was $85 \%$ at $100{ }^{\circ} \mathrm{C}$.

\section{Influence of initiator concentration}

To understand the initiator concentration's effectiveness on the synthesised terpolymer yield, a series of polymerisation was conducted with varying amounts of BPO (between 0.5 and also $2.5 \mathrm{wt} \%$ ) at fixed reaction parameters of $6 \mathrm{~h}$ at $100{ }^{\circ} \mathrm{C}$ and also BA:SMA:MA ratio of $1: 1: 1$, as depicted in Fig. 7.

As shown in Fig. 7, the terpolymer yield started increasing from 65 to $87 \%$ when the initiator's concentration escalated from 0.5 to $1.5 \mathrm{wt} \%$. This is because the free radical concentration of the initiator molecules in the polymerisation medium elevates as the initiator concentration increases. Such radicals abstract the hydrogen atom from the monomer molecules and form active locations on the polymer backbone. Also, the increase in the initiator's concentration enhanced the quantity of radical species. These active polymeric chains undergo chain transfer reactions with monomer molecules, resulting in the creation of much more active sites on the Polymer's backbone; this agrees with the results published previously by (Iş1klan et al. 2010). Consequently, the polymerisation yield rises along with the chain transfer as well as the hydrogen abstractions.

However, beyond this concentration (1.5 wt $\%$ ), the yield of reaction decreases slightly with increasing initiator concentration due to escalating the number of radicals in the tures and, usually, do not lead to any improvement to the

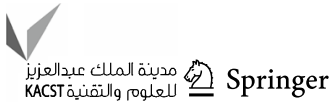




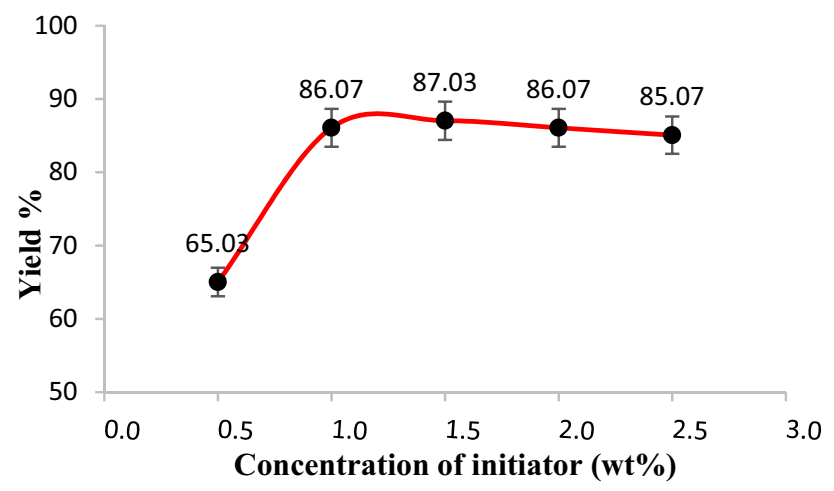

Fig. 7 PPD yield at different initiator concentration

medium, which leads to creating more nucleation sites. Therefore, when expanding the initiator to $2 \mathrm{wt} \%$, the chain transfer on the backbone of the polymer decreases. This is because the aggregation process between the monomer chains reached a sufficient point to react with the radicals. Apart from that, the greater free radical initiation rate results in quicker initial consumption of monomer, but also results in a shorter kinetic chain length and enhances the chain termination possibility by the initiator as per similar outcomes obtained by (Christian et al. 2000). Therefore, the rise in the initiator concentration above a critical value of $1.5 \mathrm{wt} \%$ leads to excessive radical concentration in the polymerisation media. Thus, the termination rate increment, mainly through bimolecular collisions among two chain radicals, that are assisted by the primary free radicals' species abundance as concluded formerly by (Kumar et al. 2019). Therefore, the ideal initiator concentration condition is $1.5 \mathrm{wt} \%$, whereby the most significant yield was attained at $87 \%$.

\section{Effect of reaction time}

The time of reaction plays an essential role in the polymerisation process. Therefore, the series of synthesised terpolymers of poly(BA-co-SMA-co-MA) were carried out at numerous polymerisation times. The reaction temperature, initiator concentrations, and monomer concentrations were remained constant at $100{ }^{\circ} \mathrm{C}, 1.5 \mathrm{wt} \%$, and $1: 1: 1$, respectively.

As depicted in Fig. 8, the synthesised terpolymer yield percentage escalated from 70 to $90 \%$ after the time was increased from 4 to $8 \mathrm{~h}$. This is because of an increase in the extent of propagation and initiation of the monomers' polymerisation within $24 \mathrm{~h}$. Furthermore, the enhancement in the polymerisation yields up to $8 \mathrm{~h}$ may be due to the increasing quantity of active spots on the polymer backbone and monomer molecules' addition to the growing chains.

However, the yield percentage no longer increased at longer reaction times and remained stagnant at around $90 \%$.

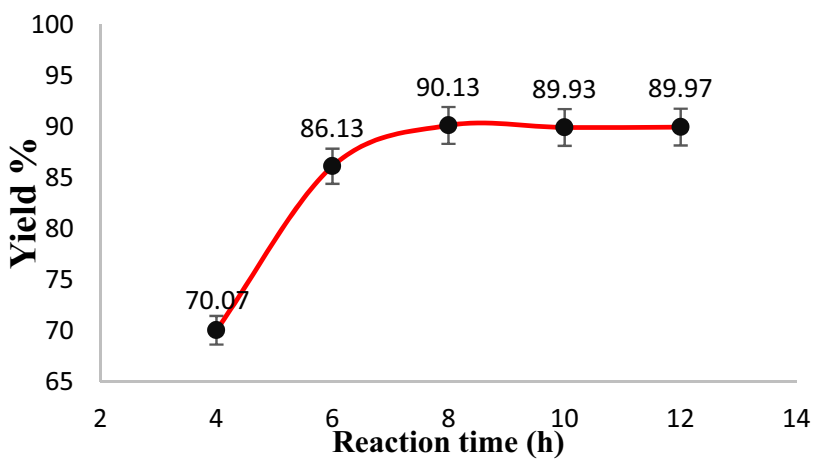

Fig. 8 Influence of reaction time on the yield of PPD

The following trend of levelling off in the yield after $8 \mathrm{~h}$ indicates that the polymerisation route was achieved with $8 \mathrm{~h}$ of reaction as per a comparable research outcome by (Zhu, et al. 2018). Besides, the percentage of polymerisation yield reaches a plateau beyond $8 \mathrm{~h}$, which could be due to progressive consumption of the monomer as well as initiator concentrations with time and the diffusion retardation after polymer formed. It could also contribute to the decreasing number of active sites available for polymerisation as the reaction proceeds. These results were found to be in agreement with the research done by a few researchers (Mostafa et al. 2018; Abu-Ilaiwi et al. 2004; Borukaev et al. 2020). Therefore, the optimum condition for polymerisation reaction time in conditions of reaction yield was $8 \mathrm{~h}$, which resulted in the greatest yield of $90 \%$.

\section{Viscosity evaluation}

Crude oil viscosity was computed experimentally; the measurements were conducted for the treated and untreated crude oil samples at different temperatures above and below the WAT of the crude oil with the range from 5 to $35^{\circ} \mathrm{C}$ and at different concentrations of the additives $(500,1000$, $1500,2000$, and $3000 \mathrm{ppm})$ and different share rate of (34, 44.20, 57.80, and $68 \mathrm{~S}^{-1}$ ). As illustrated in Fig. 9a-d, the viscosity of the crude oil declined with increasing temperature by applying (BA-co-SMA-co-MA) polymer as a flow improver. Crude oil samples showed relatively reduced viscosity with a temperature of $35^{\circ} \mathrm{C}$ but gradually increased as the temperature got closer to WAT despite the fixed shear rate (Subramanie 2019). Below the WAT, crude oil tends to be thicker, where the phases start to change from liquid to amorphous solid phase, and the degree of wax crystallisation is increased, which would lead to more wax formation. Besides, there was a significant increase in viscosity with a declined temperature for blank crude oil from 25 to $5{ }^{\circ} \mathrm{C}$. Moreover, the crude oil viscosity of the sample remains slightly constant, as crude oil's temperature exceeded WAT (over $28{ }^{\circ} \mathrm{C}$ ). The increase in temperature caused the crude 
Fig. 9 Viscosity measurement of crude oil treated with different shear rates
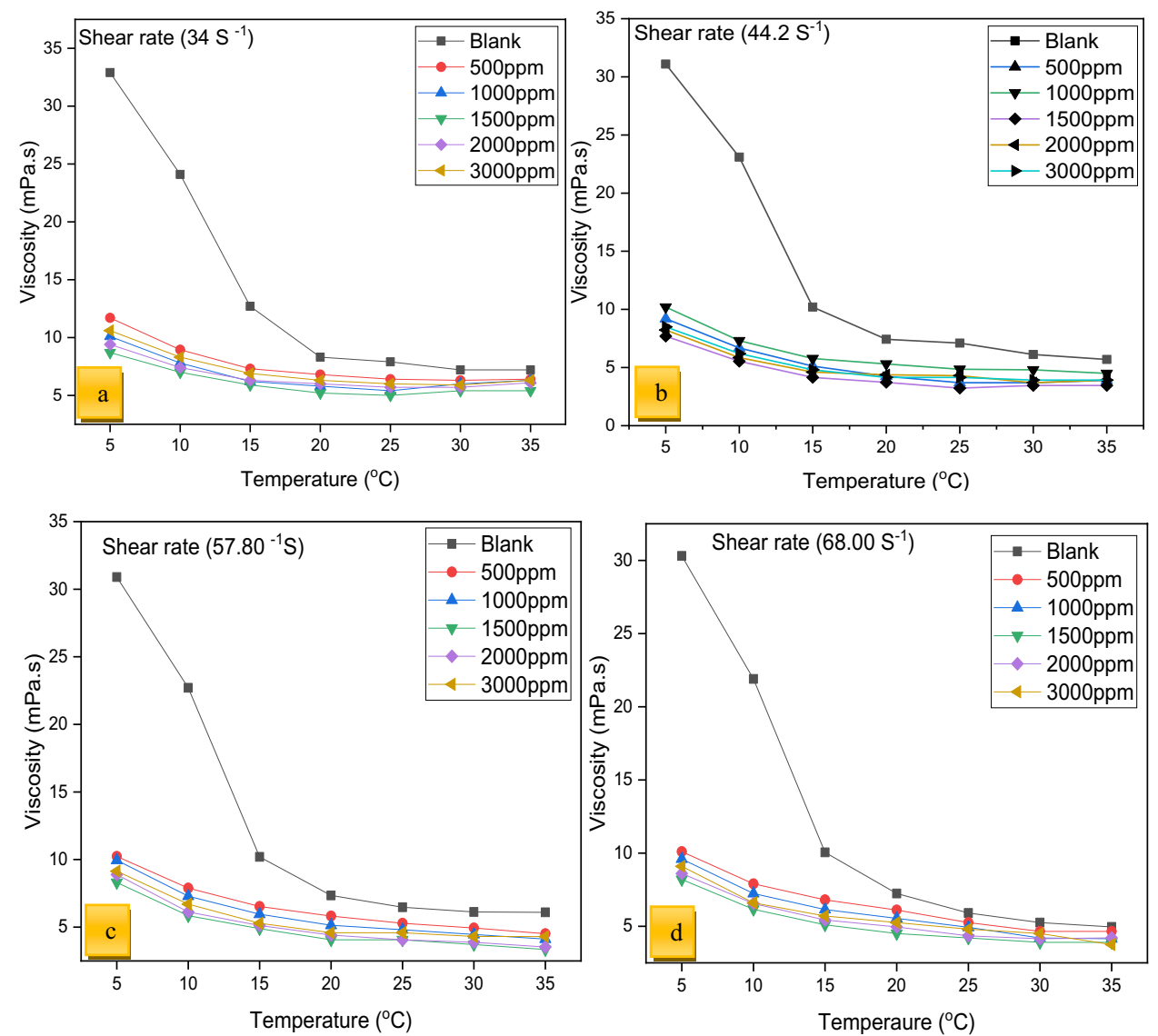

oil components with high molecular weights (such as waxes, resins, and asphaltenes) to be unable to cluster and form an aggregate; this finally affected bonds between the solid particles and reduced viscosity of the oil (Elarbe et al. 2021). Therefore, the temperature mainly affected the viscosity and chemical structure of the crude oil components with high molecular weights (Deka et al. 2018a; Lim et al. 2019). Furthermore, it was noted that all prepared polymers at different temperatures strongly reduce the crude oil viscosity. Besides, all polymer concentrations can reduce the viscosity at different ranges of temperatures and different concentrations of additives from 500 to 3000 ppm. Therefore, a significant viscosity reduction of crude oil was observed at a shear rate $34 \mathrm{~S}^{-1}$ and after the addition of $1500 \mathrm{ppm}$ concentration of Polymer at $5{ }^{\circ} \mathrm{C}$ and $35{ }^{\circ} \mathrm{C}$ of crude oil temperature by $75.33 \%$ from 33.25 to $8.2 \mathrm{mPa}$.s and $44.5 \%$ from 9.2 to $5.1 \mathrm{mPa} . \mathrm{s}$, respectively. While at $3000 \mathrm{ppm}$, the highest viscosity reduction of crude oil at $5{ }^{\circ} \mathrm{C}$ was about $68.42 \%$ from 33.25 to $10.50 \mathrm{mPa}$.s.

The capacity loss of highly soluble inhibitors to reduce crude oil viscosity could be correlated to precipitation by wax crystallisation or by the wax inhibitor nucleation process (Subramanie 2019). Also, behenyl acrylate and stearyl methacrylate have long alkyl chains, as indicated from FTIR and HNMR structural analysis. Therefore, when the viscosity reduction agent disperses crude oil molecules, long-chain can play the role of separating crude oil micelles, reducing friction to prevent the combination of oil molecules, and achieving the role of viscosity reducing agent (Deka et al. 2018a; Zhu, et al. 2018; Fang et al. 2019). Furthermore, increasing temperature from 5 to $35^{\circ} \mathrm{C}$ caused a rapid movement of wax molecular, which reduced their interaction tendency (Bello et al. 2006; Ridzuan et al. 2016a). Additionally, the relationship between the polymer and blank crude oil at the highest temperatures improved the sufficient hydrodynamic volume of the Polymer, causing the active volume fraction of the viscosity modifier to increase. This had caused the viscosity of crude oil to rise.

Furthermore, the experimental results that show the relationship between viscosity and shear rate at temperatures ranging from 5 to $35^{\circ} \mathrm{C}$ using prescribed doses 500, 1000,1500, and 2000 ppm of (BA-co-SMA-co-MA) were demonstrated in Fig. 10a-d. From these rheological data, it is noticed that the viscosity decreases approximately linearly with the increase of the shear rate at all tested temperatures, and the rate of decrease was lowered at higher shear rates, as at high shear rates, the viscosity reached a constant value. The following reasons may explain this behaviour: At temperature around the pour point and at a low shear rate, the energy exerted by shear and dissipated energy in

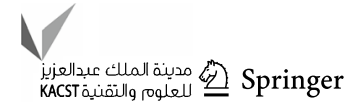


Fig. 10 Relation between shear rate and viscosity for crude oil treated with 500, 1000,1500, and 2000 ppm for (a-d), respectively
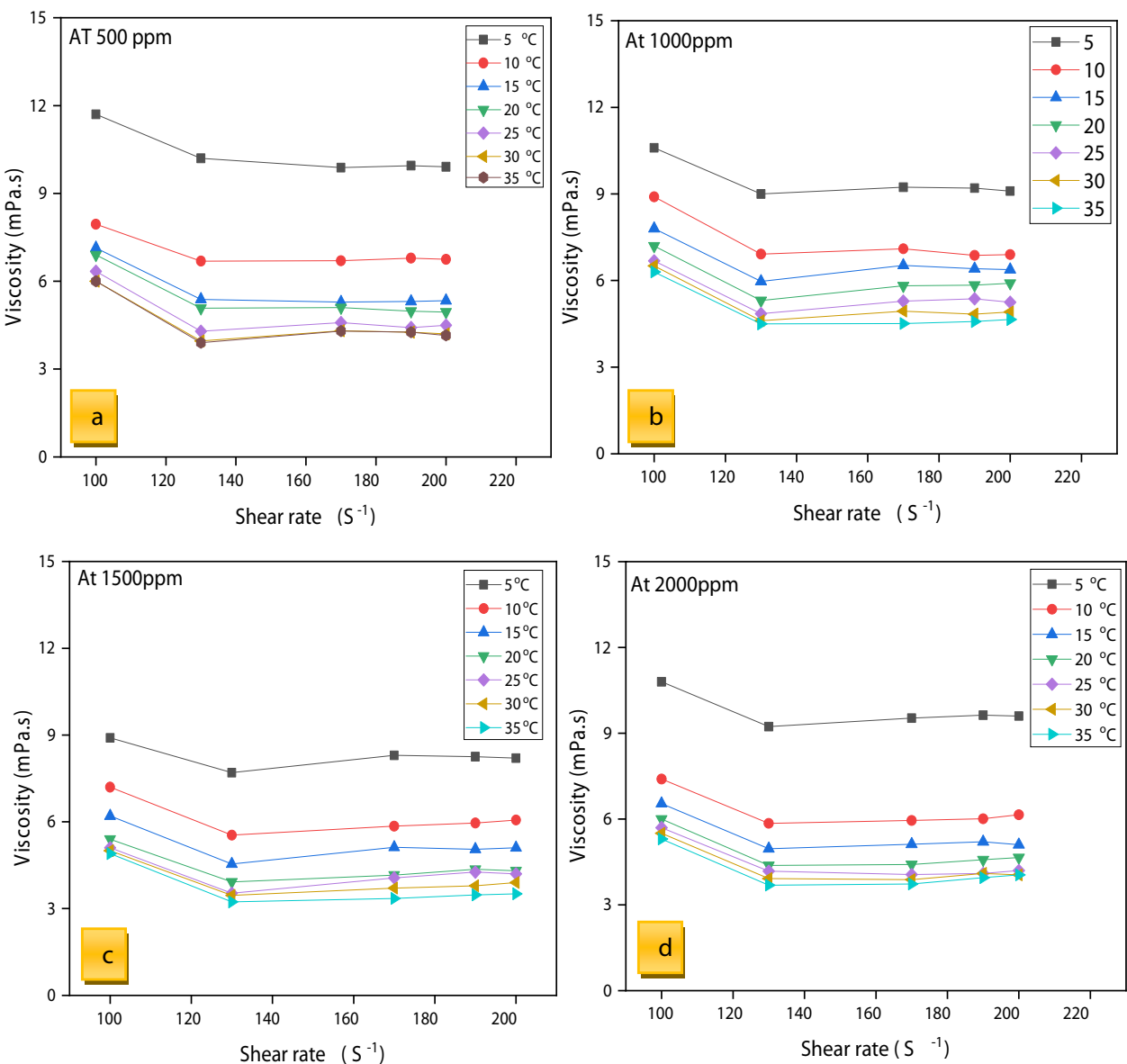

the matrix tends to break down the wax crystals partially. But by increasing the shear rate, the dissipated energy is high enough to overcome the yield stress and start flow. Upon increasing the shear rate, the size of the agglomerates decreases and this process releases some of the continuous phase initially immobilised within the agglomerates. As a result, the effective dispersed phase concentration decreases and leads to a decrease in viscosity. The viscosity decreases with increasing the shear rate until the agglomerates are completely broken down into the basic particles. Thus the waxy oil system shows non-newtonian characteristics (Soliman et al. 2018b). These findings can be attributed to the potential interactions between the polymeric additives and the constituents of waxy crude oil, resulting from dispersing asphaltene particles around the wax crystals, dissipation of agglomerates of wax crystals and its transition into small basic particles. It is worth mentioning that shearing involved in the rheological measurements assists in breaking aggregations of wax crystals, producing particles whose size and shape are easier to interact with and disperse by the additive (Soliman et al. 2018b; Li and Zhang 2003). This can explain the higher reduction in the apparent viscosity at a higher shear rate (lower dynamic viscosity), which can be due to enhancing the potential interaction between additive molecules and oil constituents, which leads to a decrease of viscosity and improves the oil flowability. On the contrary to high shearing, lowering the temperature increases the dynamic viscosity, which in turn leads to decreased extent of the interaction between additive molecules and oil constituents, leading to the decline of the efficiency of these polymeric additives in reducing rheological parameters.

\section{Cold finger}

The PIE of the prepared terpolymer at varying levels of stirring level (100, 200,300, 400,500 and $600 \mathrm{rpm})$ and at a temperature of $5^{\circ} \mathrm{C}$ has been asserted to evaluate the efficacy of the synthesised terpolymer as shown in Table 2. Throughout the experiment, two different samples of crude oil were prepared and heated above the WAT. The first one was mixed with $10 \mathrm{~mL}$ of the inhibitor at the concentration of $1500 \mathrm{ppm}$, whereas the other was used as the blank crude.

The PIE evaluation of poly(BA-co-SMA-co-MA) shows that the synthesised polymer is highly capable of decreasing the rate of deposited wax at various stirring speeds with $34-45 \%$ of wax deposition reduction. According to (Ridzuan et al. 2016b), heavy intermolecular interactions between inhibitor molecules and wax crystals in crude oil result in 
Table 2 Effects of stirring rate on the amount of wax deposits

\begin{tabular}{lcccccc}
\hline Stirring rate (rpm) & 100 & 200 & 300 & 400 & 500 & 600 \\
\hline Amount of wax deposits of blank crude oil (g) & 1.38 & 1.14 & 1.03 & 1.02 & 1.03 & 1.05 \\
Amount of wax deposits after using BA-co-SMA- & 0.81 & 0.62 & 0.63 & 0.64 & 0.63 & 0.69 \\
$\quad$ co-MA (g) & 41.3 & 45.6 & 38.5 & 36.9 & 38.5 & 34.2 \\
Paraffin inhibition efficiency, PIE (\%) & & & & & & \\
\hline
\end{tabular}

the decreasing amount of wax. Therefore, increasing the stirring rate leads to the breakdown of wax crystals, and the wax adhesion to the cold finger's surface is kept at the minimum level. These results are in agreement with the finding of Ridzuan et al. (2020). At $200 \mathrm{rpm}$, the minimum quantity of deposited wax was obtained, and the paraffin inhibitor reduced wax content by approximately $45.6 \%$. The overall accumulation rate of wax deposition fluctuated at around $0.63 \mathrm{~g}$ until the stirring rate increased to $600 \mathrm{rpm}$, where the deposited wax increased marginally to $0.69 \mathrm{~g}$. This can be explained by the fact that the cold finger temperature was set below its wax appearance temperature. Therefore, it is believed that the crude oil at the cold finger area will show non-Newtonian behaviour. By introducing a stirring rate, the heat transfer produced by the stirring of the impeller to the cold finger increased. This activity changed the internal energy of the involved system. Nevertheless, changing the temperature around the cold finger also changed the rheology of the wax deposit. However, when the samples were stirred rapidly at the shear rate of $600 \mathrm{rpm}$, the deposit amount increased slightly. This happens due to the shear thickening fluid behavior resultant from a very viscous liquid. In addition, the non-Newtonian behaviour increased the tendency of the wax to precipitate out from the crude oil to form waxes through the crystallisation process. Once the crystals have been created, the tendency of the crystal to aggregate is higher. A similar result has been reported previously by (Ridzuan et al. 2015). In a nutshell, these results show that the best wax reduction was obtained at a stirring rate of $200 \mathrm{rpm}$.

Table 3 demonstrates the performance of the paraffin inhibition of poly(BA-co-SMA-co-MA) at a steady stirring rate of $200 \mathrm{rpm}$ and different operating temperatures of (5, $10,15,20$, and $25^{\circ} \mathrm{C}$ ). When poly(BA-co-SMA-co-MA) was employed as a wax inhibitor at $5{ }^{\circ} \mathrm{C}$, the maximum PIE (45.6\%) was obtained. Furthermore, the volume of wax slightly decreased at elevated temperatures as crude oil's temperature was near its WAT. As the temperature dropped, poly(BA-co-SMA-co-MA) showed its capability to reduce the amount of wax deposition. Fig. 11 demonstrates the wax precipitated on the cold finger at $5{ }^{\circ} \mathrm{C}$ and $20{ }^{\circ} \mathrm{C}$, whereas the crude oil temperature was far from WAT. As a result, the cold finger had a high amount of wax deposits around it. Nevertheless, this finding indicates that wax formulation is influenced by temperature.

\section{Pour point measurement}

The impact of the prepared polymeric additive in depressing the pour point of the Malaysian crude oil was studied by incorporating a varying amount of these additives into oil (100-3000 ppm). In addition, different PPDs with different mole ratio were prepared to study the mole ratio effect of monomers on the pour point. The pour points of the crude oil beneficiated with and without PPD are listed in Table 4.

The pure crude oil sample initially had a high pour point of $11{ }^{\circ} \mathrm{C}$, and adding the synthesised PPD helped reduce the pour point of the crude sample to a greater extent. The results revealed that the pour point value was gradually decreased with the increasing dosage of these polymeric additives. However, this decrease was more when adding PPD1 polymeric additive to oil at a dosage of $1500 \mathrm{ppm}$ led to depressing the pour point from 11 to $-3{ }^{\circ} \mathrm{C}$. Therefore, the optimum concentration that achieved the best performance is $1500 \mathrm{ppm}$ for all used molar ratios at which the lowest pour point value was observed. Meanwhile, the dosage of $2000 \mathrm{ppm}$ was required from PPD2 to obtain around the same impact of $\left(\Delta \mathrm{PP}=13{ }^{\circ} \mathrm{C}\right)$. In this regard, it is worth mentioning that these polymeric additives were considered efficient when achieving $\Delta \mathrm{PP} \geq 14{ }^{\circ} \mathrm{C}$. However, most comparable polymeric additives are considered efficient at $\Delta \mathrm{PP} \geq 7{ }^{\circ} \mathrm{C}$ that can be obtained using only $2000 \mathrm{ppm}$ of PPD3 or 3000 ppm of PPD4. The depression in the pour point is mainly due to hindering the crystallisation of wax.
Table 3 Effects of temperature on the amount of wax deposits

\begin{tabular}{|c|c|c|c|c|c|}
\hline Temperature $\left({ }^{\circ} \mathrm{C}\right)$ & 5 & 10 & 15 & 20 & 25 \\
\hline Amount of wax deposits of blank crude oil (g) & 1.14 & 0.77 & 0.51 & 0.22 & 0.08 \\
\hline $\begin{array}{l}\text { Amount of wax deposits after using BA-co-SMA- } \\
\text { co-MA (g) }\end{array}$ & 0.62 & 0.50 & 0.32 & 0.18 & 0.06 \\
\hline Paraffin inhibition efficiency, PIE (\%) & 45.6 & 35.06 & 36.60 & 19.70 & 20.83 \\
\hline
\end{tabular}


Fig. 11 Cold finger impeller with wax deposited at different temperatures $\mathbf{a} 5{ }^{\circ} \mathrm{C}$ and $\mathbf{b}$ $20{ }^{\circ} \mathrm{C}$
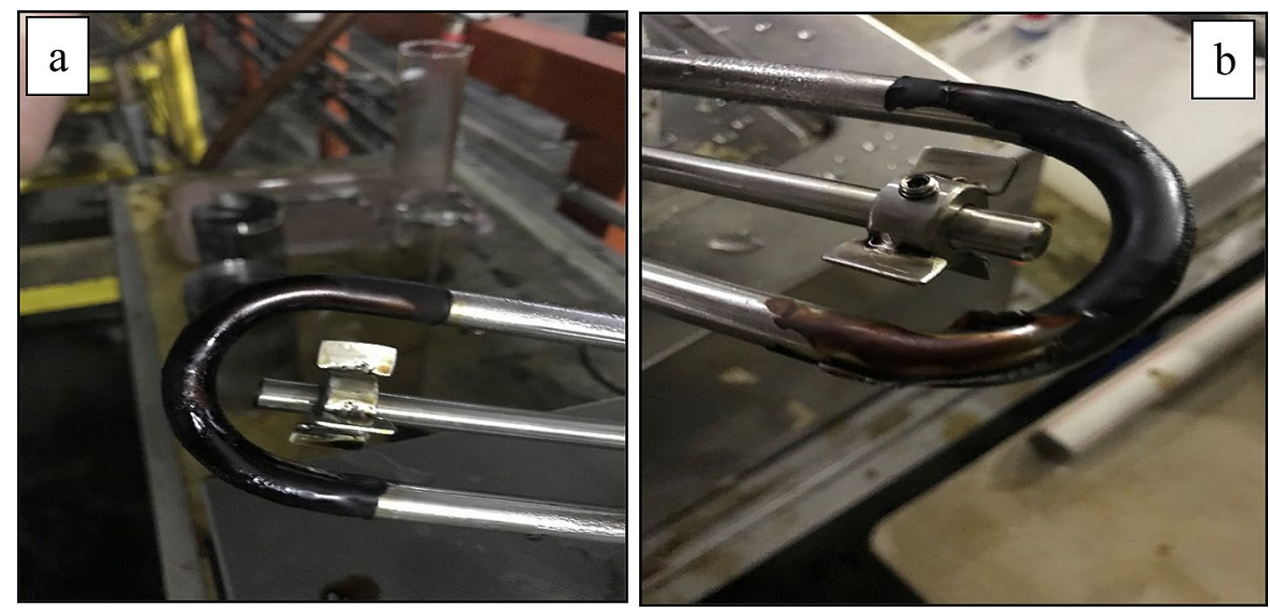

Table 4 The effect of terpolymeric additives on the pour point of crude oil

\begin{tabular}{lllllllll}
\hline Polymer code & $\begin{array}{l}\text { Polymer composition } \\
\text { (BA-co-SMA-co-MA) }\end{array}$ & \multicolumn{3}{c}{ Pour point temperatures $\left({ }^{\circ} \mathrm{C}\right)$ at different concentrations } \\
\cline { 3 - 9 } & Nil & 100 & 500 & 1000 & 1500 & 2000 & 3000 \\
\hline PPD1 & $1: 1: 1$ & 11 & 3 & 2 & 0 & -3 & -1 & 1 \\
PPD2 & $2: 1: 1$ & 11 & 3 & 2 & 1 & -2 & -2 & 1 \\
PPD3 & $1: 2: 1$ & 11 & 4 & 3 & 2 & 0 & 4 & 4 \\
PPD4 & $1: 1: 2$ & 11 & 4 & 4 & 3 & 2 & 3 & 4 \\
\hline
\end{tabular}

Polymeric additive chains are dispersed into the oil phase and interpose the wax crystals forming lamella, decreasing the interlocking forces between such nuclei of wax crystals and inhibiting their growth. It is recognised that co-crystallising or adhering wax lamella with polymer chains of additive leads to structural transition for the paraffinic wax from platelet-like to spherulitic crystal structure, which is significantly correlated with lowering the pour point; these results are in agreement with (Soliman et al. 2018b; Machado et al. 2001b). Furthermore, increasing the concentration of the polymeric additives to $3000 \mathrm{ppm}$ leads to a slight increase in the pour point. This is because every additive's pour point decreases up to an optimum concentration; after that, the pour point increases again with its increasing concentration because, after a particular concentration, PPD crystals themselves form linkages with the waxy hydrocarbon present in the oil. As a result, the polymer molecules become bulkier and less soluble with their increasing concentration, making them less effective, as reported previously by Singh and Talukdar (2021); Deka et al. 2018b).

The pour points of the crude oil containing terpolymer at molar ratio 1:1:1 mol are more efficient in reducing Malaysian crude pour point to a significant extent than other molar ratios presented in Table 4 . This means that the terpolymers, made with equal mole ratios of the used monomers, were better than those made with different molar ratios. A possible mechanism explaining these results is that PPD1 had side chains that were not identical in length. In contrast, the other terpolymers had more identical side chains when the ratio of monomers doubled. Therefore, there were more spaces among the PPD1 molecules than other terpolymer molecules because of the different side chain lengths (Jung et al. 2011). Consequently, the probability of forming network structures among the paraffin crystals co-crystallised with side chains of the terpolymers became lower. Thus, the paraffin crystals could form networks when the temperature decreased more, and the crude oil could not flow. Furthermore, these results may also be explained by matching long-chain alkyl acrylate moieties in the terpolymer backbone with the average carbon number of oil wax. It is also apparent that PPD2 terpolymers reduce the pour point of the tested crude oil to some extent more than PPD3 and PPD4 terpolymer. This may be attributed again to the high presence of long alkyl side chains of behenyl acrylates, making them more efficient additives. There long alkyl side chains afford favourable adsorption sites for wax crystals while keeping them separated by the polar centres, as similarly concluded by (Hao et al. 2019).

On the other hand, the effectiveness of the polymeric structure with high molar content of stearyl methacrylate and maleic moieties as PPDs was evaluated in PPD3 and PPD4 at different concentrations. The pour point of tested crude oil with a high molar ratio of SMA and MA performs well as PPDs at $1500 \mathrm{ppm}$. This means that at this concentration, the additive co-crystallises with paraffin and modifies their crystals. The loss of efficiency observed at high concentrations may be ascribed to the pure terpolymer 
precipitation or crystallisation itself as a nucleating agent. In addition, we observed that an increase in the molar fraction of the alkyl methacrylate monomer, in general, decreased the pour point values relative to the maleic anhydride monomer. For example, the molar fractions of BA-co-SMA-co-MA were (1:2:1) in sample PPD3 and (1:1:2) in PPD4, and the pour points of the crude oils containing $1500 \mathrm{ppm}$ were $0{ }^{\circ} \mathrm{C}$ and $2{ }^{\circ} \mathrm{C}$, respectively. This result was related to the number of the side chains of the polymers. The increase in the molar fraction of the methacrylate monomer compared to the maleic anhydride monomer meant that the number of side chains increased. As the number of the side chains increased, the possibility of co-crystallisation with the side chains and paraffin increased; hence, the pour point decreased, these results are in line with (Al-Odayni et al. 2020). The mechanism of these results can be explained as the paraffin crystals appeared and grew in the crude oil as the temperature dropped. At this moment, the polymer molecules which are played a role in molecular orientation and the nucleating process. The side chains of the polymers interacted and cocrystallised with the paraffin, whereas the backbone and polar end groups limited such crystallisation. This prevented the crystals from forming a network and a gel-like structure. Therefore, the pour point of the crude oil decreased when the (BA-co-SMA-co-MA) polymer was added as PPD; this conclusion agrees with a previous observation by El-Ghazawy and Farag (2010); Ragunathan et al. 2020).

\section{Conclusion}

A novel polymer of poly(BA-co-SMA-co-MA) as pour point depressant was formulated and used to improve the crude oil pipeline flowability. The most excellent poly(BAco-SMA-co-MA) yield was $90 \mathrm{wt} \%$, which was observed at the following optimum polymerisation reaction environments: reaction time of $8 \mathrm{~h}$, reaction temperature of $100{ }^{\circ} \mathrm{C}$, and initiator concentration of $1.5 \mathrm{wt} \%$ and monomers ratio (BA:SMA:MA) of 1:1:1. The 1HNMR and FTIR results show that methacrylate moiety, alkyl chain moiety, and maleic anhydride moiety are present in the synthesised terpolymer. The prepared PPD's performance evaluation was evaluated on the basis of the crude oil viscosity reduction. At $1500 \mathrm{ppm}$, after adding PPD to crude oil, the viscosity reduced to approximately $75 \%$ from around $33.25 \mathrm{mPa}$.s for the blank crude to about $8.2 \mathrm{mPa}$.s. In the cold finger experiment, the minimum quantity of the wax deposits was obtained at $200 \mathrm{rpm}$, and the paraffin inhibitor decreased wax content by approximately $45.6 \%$. Furthermore, after the prepared PPD was applied, the maximum PIE was $45.6 \%$ at $5{ }^{\circ} \mathrm{C}$ and $200 \mathrm{rpm}$. Also, the synthesised PPD exhibited high performance in decreasing the pour point, which dropped up to $14{ }^{\circ} \mathrm{C}$ at the concentration of $1500 \mathrm{ppm}$ of
poly(BA-co-SMA-co-MA). Meanwhile, the crystallisation behaviour of wax crystals is also influenced by the new PPDs, which led to improved flowability of crude oil. Hence, the newly synthesised poly(BA-co-SMA-co-MA) terpolymer was magnificently prepared and can be utilised to resolve the crude oil flowability issue.

Funding This research was funded by University Malaysia Pahang through PGRS 1903103 and RDU1803172 grant.

\section{Declarations}

Conflict of interest The authors declare that they have no known competing financial interests or personal relationships that could have influenced the work reported in this paper.

Open Access This article is licensed under a Creative Commons Attribution 4.0 International License, which permits use, sharing, adaptation, distribution and reproduction in any medium or format, as long as you give appropriate credit to the original author(s) and the source, provide a link to the Creative Commons licence, and indicate if changes were made. The images or other third party material in this article are included in the article's Creative Commons licence, unless indicated otherwise in a credit line to the material. If material is not included in the article's Creative Commons licence and your intended use is not permitted by statutory regulation or exceeds the permitted use, you will need to obtain permission directly from the copyright holder. To view a copy of this licence, visit http://creativecommons.org/licenses/by/4.0/.

\section{References}

Abu-Ilaiwi FA, Ahmad MB, Ibrahim NA, Rahman MZA, Khairul Zaman M, Dahlan WM, Yunus ZW (2014) Optimized conditions for the grafting reaction of poly (methyl acrylate) onto rubberwood fiber. Polym Int 53(4):386-391

Aiyejina A, Chakrabarti DP, Pilgrim A, Sastry M (2011) Wax formation in oil pipelines: a critical review. Int J Multiph Flow 37(7):671-694

Alnaimat F, Ziauddin M (2020) Wax deposition and prediction in petroleum pipelines. J Pet Sci Eng 184:106385

Al-Odayni A-B, Saeed WS, Ahmed AYBH, Alrahlah A, Al-Kahtani A, Aouak T (2020) New monomer based on eugenol methacrylate, synthesis, polymerization and copolymerization with methyl methacrylate-characterization and thermal properties. Polymers 12(1): 160

Anisuzzaman SM, Abang S, Bono A, Krishnaiah D, Karali R, Safuan MK (2017) Wax inhibitor based on ethylene vinyl acetate with methyl methacrylate and diethanolamine for crude oil pipeline. IOP Conf Ser Mater Sci Eng 206(1):012074

Atta AM, El-Ghazawy R, Morsy F, Ali M, Elmorsy A (2013) Synthesis and characterization of polymeric additives and their effect on flow properties of waxy Egyptians crude oil. Global J Sci Front Res Chem 13(10):21-27

Ballard N, Asua JM (2018) Radical polymerization of acrylic monomers: an overview. Prog Polym Sci 79:40-60

Bello OO, Fasesan SO, Macaulay SR, Latinwo GK (2005) Study of the influence of xylene-based chemical additive on crude oil flow properties and paraffin deposition inhibition. Eng J Univ Qatar $18: 15-28$ 
Bello O, Fasesan S, Teodoriu C, Reinicke K (2006) An evaluation of the performance of selected wax inhibitors on paraffin deposition of Nigerian crude oils. Pet Sci Technol 24(2):195-206

Borukaev TA, Otarova RM, Salamov AK, Orlov AV (2020) Influence of different factors on the oxidizing polymerization of 3-Amino-3 -Nitrodiphenylazomethine and some properties of the received polymer. Key Eng Mater 869:234-239

Chala GT, Sulaiman SA, Japper-Jaafar A (2018) Flow start-up and transportation of waxy crude oil in pipelines-a review. J Nonnewton Fluid Mech 251:69-87

Christian P, Giles MR, Griffiths RM, Irvine DJ, Major RC, Howdle SM (2000) Free radical polymerization of methyl methacrylate in supercritical carbon dioxide using a pseudo-graft stabilizer: effect of monomer, initiator, and stabilizer concentrations. Macromolecules 33(25):9222-9227

Darvishi A, Zohuriaan Mehr MJ, Marandi GB, Kabiri K, Bouhendi H, Bakhshi H (2013) Copolymers of glycidyl methacrylate and octadecyl acrylate: synthesis, characterization, swelling properties, and reactivity ratios. Des Monomer Polym 16(1):79-88

Darvishi A, Zohuriaan Mehr MJ, Marandi GB, Kabiri K, Bouhendi H, Bakhshi H (2013) Copolymers of glycidyl methacrylate and octadecyl acrylate: synthesis, characterization, swelling properties, and reactivity ratios. Des Monomers Polym 16(1):79-88

Deka B, Sharma R, Mandal A, Mahto V (2018a) Synthesis and evaluation of oleic acid based polymeric additive as pour point depressant to improve flow properties of Indian waxy crude oil. J Petrol Sci Eng 170:105-111

Deka B, Sharma R, Mandal A, Mahto V (2018b) Synthesis and evaluation of oleic acid based polymeric additive as pour point depressant to improve flow properties of Indian waxy crude oil. J Pet Sci 170:105-111

Elarbe B, Ridzuan N, Yusoh K, Elganidi I, Abdullah N (2019) Screening of the factors for novel pour point depressant copolymer synthesis to improve the copolymer yield, In $I O P$ conference series: materials science and engineering 702(1): 012028: IOP Publishing.

Elarbe B, Elganidi I, Ridzuan N, Abdullah N, Yusoh KJMTP (2021) Influence of poly (stearyl acrylate co-behenyl acrylate) as flow improvers on the viscosity reduction of Malaysian crude oil. Mater Today: Proc 42:201-210

Elbanna S, Abd El Rhman A, Al-Hussaini A, Khalil S (2017) Synthesis and characterization of polymeric additives based on $\alpha$-Olefin as pour point depressant for Egyptian waxy crude oil. Pet Sci Technol 35(10):1047-1054

Elganidi I, Elarbe B, Abdullah N, Ridzuan N (2019) Characterization of a novel terpolymer containing maleic anhydride-co-stearyl methacrylate-co-benhely acrylate for wax inhibition application, In IOP conference series: materials science and engineering 702(1): 012027: IOP Publishing.

Elganidi I, Elarbe B, Abdullah N, Ridzuan N (2021) Synthesis of a novel terpolymer of (BA-co-SMA-co-MA) as pour point depressants to improve the flowability of the Malaysian crude oil. Mater Today: Proc 42:28-32

El-Ghazawy RA, Farag RK (2010) Synthesis and characterization of novel pour point depressants based on maleic anhydride-alkyl acrylates terpolymers. J Appl Polym Sci 115(1):72-78

Fang S, Wang M, Xu Z, Zhai L, Wang X, Xiong Y (2019) Preparation of an amphoteric flocculant having both high polymer content and low viscosity and its polymerization kinetics. Chin J Chem Eng 27(1):130-135

Farag RK (2008) Poly (cinnamoyloxy ethyl methacrylate-co-octadecyl acrylate) as flow improver for Egyptian waxy crude oils. Int $\mathbf{J}$ Polym Mater 57(3):189-202

Ghosh P, Das M (2014) Study of the influence of some polymeric additives as viscosity index improvers and pour point depressants-synthesis and characterization. J Petrol Sci Eng 119:79-84
Ghosh P, Hoque M, Karmakar G, Das MK (2017) Dodecyl methacrylate and vinyl acetate copolymers as viscosity modifier and pour point depressant for lubricating oil. Int J Indus Chem 8(2):197-205

Goswami PK, Kashyap M, Das PP, Saikia PJ, Handique JG (2019) Poly (Glycidyl Methacrylate-co-Octadecyl Methacrylate) particles by dispersion radical copolymerization. J Dispers Sci Technol 41:1-9

Hao LZ, Al-Salim HS, Ridzuan N (2019) A review of the mechanism and role of wax inhibitors in the wax deposition and precipitation. Pertanika J Sci Technol 27(1):499-526

Işıklan N, Kurşun F, İnal Mur (2010) Graft copolymerization of itaconic acid onto sodium alginate using benzoyl peroxide. Carbohydr Polym 79(3):665-672

Jadhav SA et al (2019) Recent advancements in silica nanoparticles based technologies for removal of dyes from water. Colloid Interface Sci Commun 30:100181

Jennings DW, Breitigam J (2010) Paraffin inhibitor formulations for different application environments: From heated injection in the desert to extreme cold arctic temperatures. Energy Fuels 24(4):2337-2349

Jung KM, Chun BH, Park SH, Lee CH, Kim SH (2011) Synthesis of methacrylate copolymers and their effects as pour point depressants for lubricant oil. J Appl Polym Sci 120(5):2579-2586

Kumar D, Pandey J, Khan N, Kumar P, Kundu PP (2019) Synthesize and characterization of binary grafted psyllium for removing toxic mercury (II) ions from aqueous solution. Mater Sci Eng: C 104:109900

Li N, Mao G, Shi X, Tian S, Liu Y (2018) Advances in the research of polymeric pour point depressant for waxy crude oil. J Dispers Sci Technol 39(8):1165-1171

Li H, Zhang J (2003) A generalized model for predicting non-Newtonian viscosity of waxy crudes as a function of temperature and precipitated wax 弥. Fuel 82(11):1387-1397

Lim Z, Al Salim H, Hasiholan B, Ridzuan N 2019 (Evaluation of silane-based surfactant nanohybrid as flow improver in a Malaysian light crude oil, In IOP Conference series: materials science and engineering, 469: (1)012001: IOP Publishing.

Lv P, Bin Y, Li Y, Chen R, Wang X, Zhao BJP (2009) Studies on graft copolymerization of chitosan with acrylonitrile by the redox system. Polymer 50(24):5675-5680

Machado AL, Lucas EF, González G (2001a) Poly (ethylene-co-vinyl acetate)(EVA) as wax inhibitor of a Brazilian crude oil: oil viscosity, pour point and phase behavior of organic solutions. J Petrol Sci Eng 32(2-4):159-165

Machado ALC, Lucas EF, González G (2001) Poly (ethylene-co-vinyl acetate)(EVA) as wax inhibitor of a Brazilian crude oil: oil viscosity, pour point and phase behavior of organic solutions. J Pet Sci Eng 32(2-4):159-165

Madani M, Moraveji MK, Sharifi M (2021) Modeling apparent viscosity of waxy crude oils doped with polymeric wax inhibitors. J Pet Sci Eng 196:108076

M. E. Mohyaldinn, H. Husin, N. Hasan, M. M. Elmubarak, A. M. Genefid, and M. E. Dheeb (2019) Challenges during operation and shutdown of waxy crude pipelines, In Processing of heavy crude oils-challenges and opportunities: IntechOpen. https://doi. org/10.5772/intechopen.89489

Mostafa KM, Osman E, Mahmoud RI, El-Sanabary AA (2018) Towards synthesis, characterization and properties of smart material based on chitosan using Mn-IV itaconic acid as a novel redox pair. J Polym Environ 26(8):3250-3261

Ragunathan T, Husin H, Wood CD (2020) Wax formation mechanisms, wax chemical inhibitors and factors affecting chemical inhibition. Appl Sci 10(2):479

Ridzuan N, Adam F, Yaacob Z (2015) Effects of shear rate and inhibitors on wax deposition of malaysian crude oil. Orient $\mathrm{J}$ Chem 31(4):1999-2004 
Ridzuan N, Adam F, Yaacob Z (2016) Evaluation of the inhibitor selection on wax deposition for Malaysian crude oil. Pet Sci Technol 34(4):366-371

Ridzuan N, Adam F, Yaacob Z (2016) Evaluation of the inhibitor selection on wax deposition for Malaysian crude oil. Pet Sci Technol 34(4):366-371

Ridzuan N, Subramanie P, Uyop MF (2020) Effect of pour point depressant (PPD) and the nanoparticles on the wax deposition, viscosity and shear stress for Malaysian crude oil. Petrol Sci Technol 38(20):929-935

Sabaa MW, Mohamed NA, Mohamed RR, Khalil NM, Abd El Latif SMJCP (2010) Synthesis, characterization and antimicrobial activity of poly (N-vinyl imidazole) grafted carboxymethyl chitosan. Carbohyd Polym 79(4):998-1005

Singh R, Talukdar P (2021) the Effect OF silica based nanocomposite pour point depressant on the waxy Crude oil of North-East India. Int J Eng Appl Sci Technol 5(9):147-151

Soliman EA, Elkatory MR, Hashem AI, Ibrahim HS (2018a) Synthesis and performance of maleic anhydride copolymers with alkyl linoleate or tetra-esters as pour point depressants for waxy crude oil. Fuel 211:535-547

Soliman EA, Elkatory MR, Hashem AI, Ibrahim HS (2018) Synthesis and performance of maleic anhydride copolymers with alkyl linoleate or tetra-esters as pour point depressants for waxy crude oil. Fuel 211:535-547

Song Y, Ren T, Fu X, Xu X (2005) Study on the relationship between the structure and activities of alkyl methacrylate-maleic anhydride polymers as cold flow improvers in diesel fuels. Fuel Process Technol 86(6):641-650

Speight JG (2015) Handbook of petroleum product analysis. Wiley, Hoboken

Subramanie PA, Padhi A, Ridzuan N, Adam F (2020) Experimental study on the effect of wax inhibitor and nanoparticles on rheology of Malaysian crude oil. J of King Saud Univ-Eng Sci 32(8):479-483

Subramanie PA, Padhi A, Ridzuan N, Adam F (2020) Experimental study on the effect of wax inhibitor and nanoparticles on rheology of Malaysian crude oil. J of King Saud Univ-Eng Sci 32(8):479-483

Than DV, Chuong TH, Tuy DQ (2017) Synthesis copolymer use to reduce pour point temperature of diamond crude oil, In AIP conference proceedings, 1878(1): 020002: AIP Publishing LLC.

Upadhyay M, Saha DK, Ghosh P (2018) Dodecylmethacrylate-Behenyl Acrylate copolymers as potential multifunctional additive for lubricating oil. J Sci Ind Res 77:652-656

Wang F et al (2011) The effect of nanohybrid materials on the pourpoint and viscosity depressing of waxy crude oil. Chin Sci Bull 56(1):14-17

Wang Z, Xu Y, Zhao Y, Li Z, Liu Y, Hong J (2019) Role of shearing dispersion and stripping in wax deposition in crude oil pipelines. Energies 12(22):4325
White M, Pierce K, Acharya T (2018) A review of wax-formation/ mitigation technologies in the petroleum industry. SPE Prod Oper 33(03):476-485

Wu Y, Ni G, Yang F, Li C, Dong G (2012) Modified maleic anhydride co-polymers as pour-point depressants and their effects on waxy crude oil rheology. Energy Fuels 26(2):995-1001

Yang F, Zhao Y, Sjöblom J, Li C, Paso KG (2015a) Polymeric wax inhibitors and pour point depressants for waxy crude oils: a critical review. J Disp Sci Technol 36(2):213-225

Yang F, Paso K, Norrman J, Li C, Oschmann H, Sjöblom J (2015b) Hydrophilic nanoparticles facilitate wax inhibition. Energy Fuels 29(3): 1368-1374

Yang F, Yao B, Li C, Shi X, Sun G, Ma X (2017) Performance improvement of the ethylene-vinyl acetate copolymer (EVA) pour point depressant by small dosages of the polymethylsilsesquioxane (PMSQ) microsphere: an experimental study. Fuel 207:204-213

Yang F et al (2018) Comb-like Polyoctadecyl Acrylate (POA) wax inhibitor triggers the formation of heterogeneous waxy oil gel deposits in a cylindrical couette device. Energy Fuels 32(1):373-383

Yao B, Li C, Yang F, Zhang Y, Xiao Z, Sun G (2016) Structural properties of gelled Changqing waxy crude oil benefitted with nanocomposite pour point depressant. Fuel 184:544-554

Zhou M, He Y, Chen Y, Yang Y, Lin H, Han S (2015) Synthesis and evaluation of terpolymers consist of methacrylates with maleic anhydride and methacrylic morpholine and their amine compound as pour point depressants in diesel fuels. Energy Fuels 29(9):5618-5624

Zhu X, Gu Y, Chen G, Cheng Z, Lu J (2004) Synthesis of poly (octadecyl acrylate-b-styrene-b-octadecyl acrylate) triblock copolymer by atom transfer radical polymerization. J Appl Polym Sci 93(4):1539-1545

Zhu L, Jing X, Wang S, Chen J, Xia D, Li A (2015) Screening and evaluation of types and ratio of monomers of oil soluble viscosity reducing agent for Shengli super heavy oil. Pet Sci Technol $33(4): 452-459$

Zhu L et al (2018) High viscosity-reducing performance oil-soluble viscosity reduction agents containing acrylic acid ester as monomer for heavy oil with high asphaltene content. J Petrol Sci Eng $163: 37-44$

Zhu L et al. (2018) Screening of synthesis conditions of polymers and the effects on viscosity reduction performance, In IOP conference series: earth and environmental science, 108(2): 022032: IOP Publishing.

Publisher's Note Springer Nature remains neutral with regard to jurisdictional claims in published maps and institutional affiliations. 